\title{
Tyrosine-Protein Kinase Mer
}

National Cancer Institute

\section{Source}

National Cancer Institute. Tyrosine-Protein Kinase Mer. NCI Thesaurus. Code C26383.

Tyrosine-protein kinase Mer (999 aa, 110 kDa) is encoded by the human MERTK gene.

This protein is involved in ligand-dependent signaling. 